\title{
Single Reflect-Mirror Laser Communication Tracking-Pointing System Load Technology for Micronanosatellite
}

\author{
Tie Chi $\mathbb{D},{ }^{1,2}$ Lizhong Zhang $\mathbb{D}^{2}$, and Lixin Meng $\mathbb{D}^{2}$ \\ ${ }^{1}$ Engineering Institute, Jilin Business and Technology College, Changchun, Jilin 130507, China \\ ${ }^{2}$ Electro Mechanic Engineering College, Changchun University of Science and Technology, Changchun, Jilin 130022, China
}

Correspondence should be addressed to Lizhong Zhang; 2016200056@mails.cust.edu.cn

Received 24 November 2021; Accepted 17 December 2021; Published 13 January 2022

Academic Editor: Miaochao Chen Copyright ( 2022 Tie Chi et al. This is an open access article distributed under the Creative Commons Attribution License, which
permits unrestricted use, distribution, and reproduction in any medium, provided the original work is properly cited.

\begin{abstract}
In order to realize low-orbit microsatellite laser communication, L- and U-frame structures are designed, respectively, for the payload of single-lens reflex (SLR) laser communication tracking and pointing system. According to the characteristics of each load structure, the detailed system design is carried out, and the modal analysis is carried out on the key structural parts of the $\mathrm{L}$ - and U-frames to ensure the reliability of each load structure. The pointing accuracy of the two load structures is also calculated and analyzed. Finally, the conclusion is that both of the two load structures can meet the technical and accuracy requirements of low-orbit communication, but obviously, the U-frame structure has higher accuracy, greater pitching angle, and better reliability; eventually, the U-frame structure is adopted in this design. Then, we have completed the manufacture and assembly of the principle prototype and carried out a vibration test experiment on the principle prototype. The results show that the U-type loading structure SLR laser communication tracking and pointing system achieves the expected design purpose and can meet the technical requirements of the low-orbit microsatellite laser communication.
\end{abstract}

\section{Introduction}

Microsatellite laser communication tracking and pointing system has the characteristics of small size, light weight, low cost, short cycle, and good performance [1-3], hence the rapid development [4-6]. Because the laser beam width is narrower than in the RF or microwave range, the transmitted optical power may be significantly reduced. This leads to development of miniature communication systems with extremely low power consumption $[7,8]$.

In recent years, the international space technology field attaches great importance to the development of small satellites, and the structural design technology of the laser communication system mounted on the satellite has also made new progress [9-11]. The SLR tracking and pointing system has the advantages of small moment of inertia and high reliability compared with other forms and has a great advantage in the application of laser communication network in space satellites [12].

\section{Design of Principle Prototype APT Subsystem of Main Optical Terminal Machine}

General APT (Acquisition, Pointing and Tracking) subsystem is composed of rough tracking control subsystem and precise tracking control subsystem $[13,14]$. The rough tracking subsystem can be divided into visual axis stabilization ring, open pointing ring, and dynamic tracking ring according to its functions [15]. The three control rings share the same actuator. According to the technical requirements of space microsatellite laser communication and project design tasks, the main indexes of APT subsystem design rough tracking unit are as follows: 


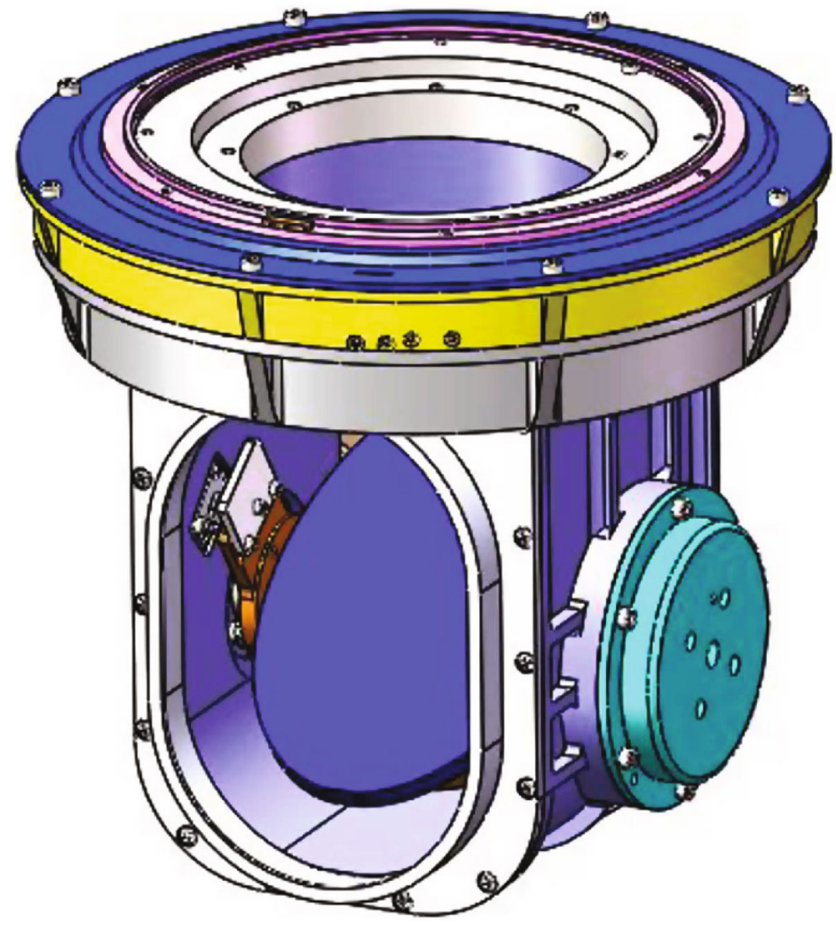

Figure 1: U-type structure.

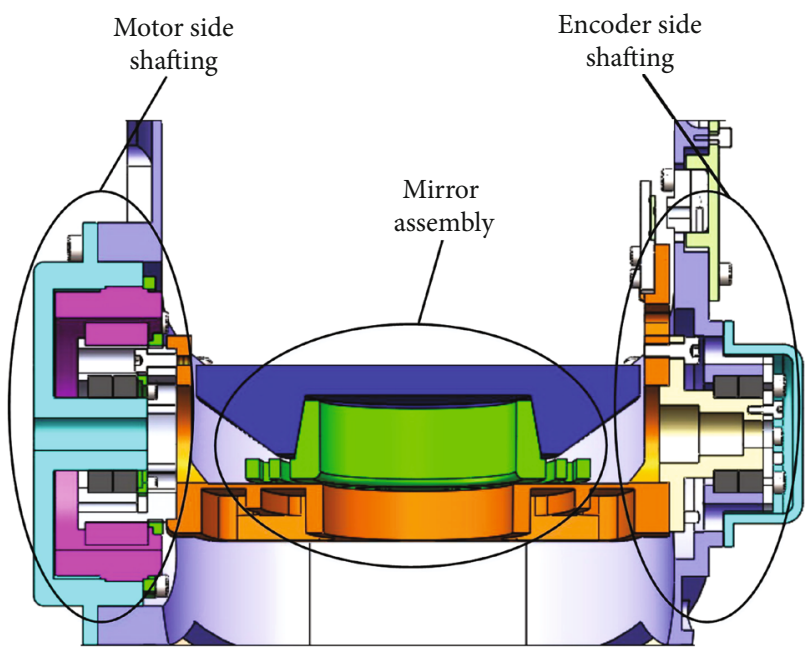

Figure 2: Elevation axis structure.

(i) Rough tracking accuracy: $150 \mu \mathrm{rad}$

(ii) Maximum angular velocity: $2 \% \mathrm{~s}(34 \mathrm{mrad} / \mathrm{s})$

(iii) Maximum angular acceleration: $2^{\circ} / \mathrm{s}^{2}\left(34 \mathrm{mrad} / \mathrm{s}^{2}\right)$

(iv) Single mirror azimuth rotation range: $\pm 60^{\circ}$

(v) Single mirror elevating rotation range: $\pm 8^{\circ}$

2.1. Design of the Payload Structure of U-Frame Rough Tracking Unit. The optical receiver adopts single-lens reflex servo turntable. The advantage of the SLR servo turntable is that the core elements such as the telescope unit, subsequent optical path unit, detector, and laser are fixed and

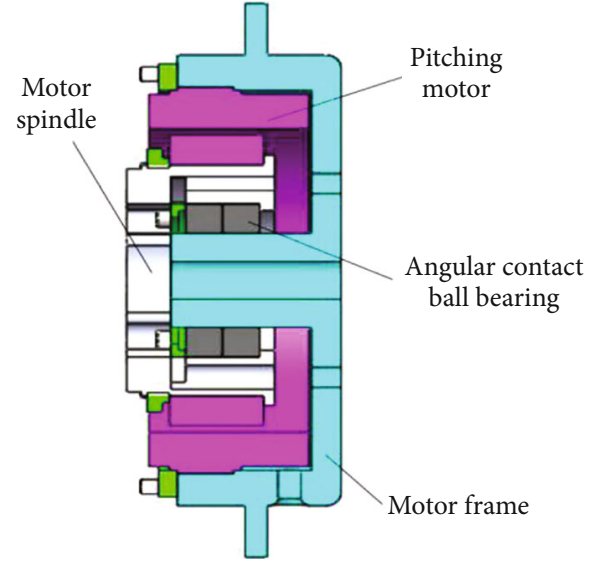

Figure 3: Motor shafting structure.

do not need to be moved due to the adjustment of the visual axis, which is conducive to improving the reliability of the system and reducing the disturbance to the platform. The motion load has only the plane mirror part, and the moment of inertia is small, which is helpful to improve the bandwidth and tracking precision of the servo system. The overall structure of the U-frame rough tracking unit is shown in Figure 1. According to the 3D modeling analysis of the turntable, the total weight of the SLR servo turntable is $4.5 \mathrm{~kg}$, the effective optical aperture is $\varphi 86 \mathrm{~mm}$, and the external envelope size is $\varphi 214 \mathrm{~mm} \times 199 \mathrm{~mm}$.

2.1.1. Design of Mirror Components. The motion range of the elevation axis of the $\mathrm{U}$-frame rough tracking unit is $-10-+8^{\circ}$, and the effective aperture diameter is $\varphi 86 \mathrm{~mm}$. In order to ensure the maximum energy utilization of the mirror, the effective aperture of the reflector should be larger than the effective aperture. The mirror is made of microcrystalline glass, and the soft joints of the mirror are made of Invar alloy. By adjusting the ratio of Invar alloy material, the line expansion coefficient can be guaranteed to match the microcrystal.

2.1.2. Elevation Axis Design. In the design of elevation axis, the left and right half axes are mainly used to support the mirror parts, and the bearings are fixed at one end and moved at the other end, so as to improve the elevation axis rotation accuracy and compensate the temperature deformation. The motor and fan-shaped grating are, respectively, installed on the two half axes. The structure is shown in Figure 2.

(1) Motor Shafting Design. In order to compress the axial size as much as possible, the elevation motor and bearing are used in sheathing the axis installation, that is, the bearing is installed in the center hole of the motor and connected to the motor stator through U-shaped sleeve, the motor rotor is connected to the main axis, and the main axis is connected to the back plate of the mirror with flange. This sheathing axis installation greatly reduces the axial size. A pair of $\mathrm{p} 4-$ grade angular contact bearings is used, and the bearing clearance is eliminated by face to face installation. The 
TABLE 1: Main parameters of pitching motor.

\begin{tabular}{lccccc}
\hline Motor & $\begin{array}{c}\text { Voltage at peak } \\
\text { torque }(\mathrm{V})\end{array}$ & Electricity (A) & $\begin{array}{c}\text { Continuous } \\
\text { blocked } \\
\text { torque }(\mathrm{nm})\end{array}$ & Peak torque $(\mathrm{nm})$ & $\begin{array}{c}\text { Load inertia }\left(\mathrm{kg} \cdot \mathrm{m}^{2}\right) \\
(\mathrm{rad} / \mathrm{min})\end{array}$ \\
\hline Brushless DC torque motor & 24 & 0.773 & 0.019 & 0.337 & $2.131 E-05$ \\
\hline
\end{tabular}

bearing and axis are not constrained in axial direction and can slide freely, thus solving the axial displacement problem caused by temperature change. The shafting is installed with a limiting block, limiting the working range of the elevating angle. Its structure is shown in Figure 3.

Through comparing many kinds of motors, the splittype DC torque motor is adopted. The split-type DC torque motor has the characteristics of stable torque output, such as good speed regulating performance, strong overload capacity, and fast response speed, etc. It is very suitable for the photoelectric turntable with higher requirements on precision. In order to make the output torque of the azimuth motor meet the use requirement, the torque of azimuth motor is estimated. According to the moment formula [16]

$$
M=k\left(M_{f}+J \varepsilon_{\max }\right) .
$$

In this formula, $k$ is the safety factor and the value range is $1.5 \sim 2, M_{f}$ is the friction torque $\left(M_{f}=0.01 \mathrm{~N} \cdot \mathrm{m}\right), J$ is the moment of inertia $\left(J=0.002 \mathrm{~kg} \cdot \mathrm{m}^{2}\right)$, and $\varepsilon_{\max }$ is the maximum angular acceleration:

$$
\begin{aligned}
\varepsilon_{\max } & =2^{\circ} / \mathrm{s}^{2} \\
J \varepsilon_{\max } & =0.002 \times \frac{2}{360} \times 6.28=7.0 \times 10^{-5} \mathrm{Nm}
\end{aligned}
$$

The calculated output torque of the motor should be greater than $M_{\max }=0.01 \mathrm{Nm}$. Allied Motion's brushless DC torque motor was selected after comparative analysis, and its main technical indexes are shown in Table 1.

(2) The Grating End Shafting Design. The grating end shafting adopts 1 to $\mathrm{p} 4$-grade matching angular contact bearings, which are installed face to face and fixed on the U-frame and principal axis, respectively, through the inner and outer pressure rings. The grating shafting structure is shown in Figure 4.

The elevating rotation angle is small, and through the comparison of various sensors, the fan-type grating and reading head produced by the MicroE Company are finally adopted. The fan-type grating is simple in structure, easier to install and lighter in weight, has higher accuracy in angle measurement, and does not need more maintenance. The grating parameters are shown in Table 2.

2.1.3. Azimuth Rotation Shafting Design. The rotation range of azimuth shaft system is required to be $\pm 60^{\circ}$, but the actual rotation range of this design is $\pm 150^{\circ}$, which is much better than the design requirements and meets the accuracy

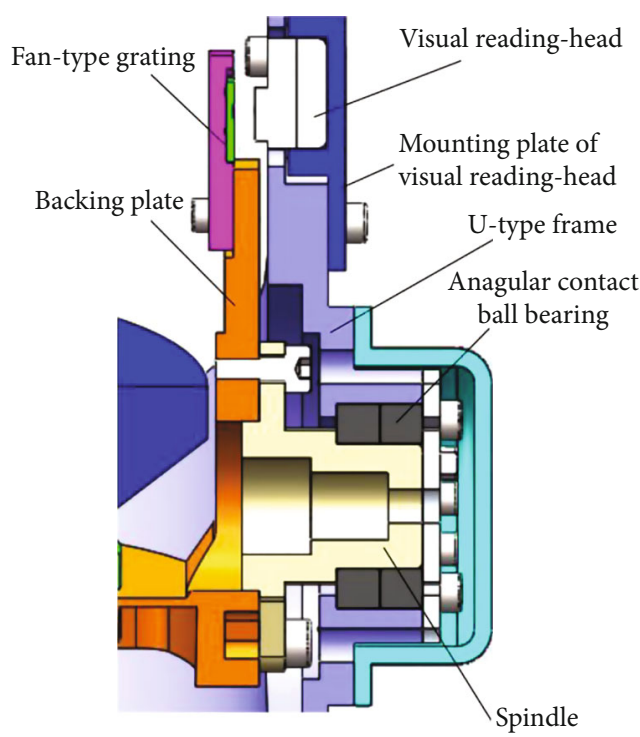

FIgURE 4: Grating side shafting structure.

requirements. As shown in Figure 5, the azimuth shaft system is mainly composed of the azimuth motor, base, bearing, U-frame, grating, reading head, protective cover, and conductive slip ring.

Through the comparison of many kinds of motors, it is decided to adopt the split DC torque motor. In order to make the output torque of azimuth motor meet the requirements of use, the torque of azimuth motor is estimated.

The safety factor is $1.5 \sim 2$, friction torque is $M_{\mathrm{f}}=0.1$ $\mathrm{N} \cdot \mathrm{m}$, rotational inertia is $J=0.019 \mathrm{~kg} \cdot \mathrm{m}^{2}$, and maximum angular acceleration is $\varepsilon_{\max }=2 \% \mathrm{~s}^{2}$.

$$
J \varepsilon_{\max }=0.019 \times \frac{2}{360} \times 6.28=6.6 \times 10^{-4} \mathrm{Nm}
$$

$M_{\max }=0.1 \mathrm{Nm}$. According to this calculation, J150LST01B is selected by the Chengdu Micro-Precision Motor Co., Ltd.; the motor parameters are shown in Table 3.

RGSZ20-S flexible grating band is produced by the Renishaw Company of the UK, which is used for the angular displacement sensor of the azimuth axis, and the corresponding reading head type is T1600-10M.

Since the azimuth center light is adopted in the design, and the azimuth axis system adopts the large hollow axis system, in order to maximize the axial size of the compressing mirror driven turntable, the bearing and grating are installed with the spigot shaft type. The motor shaft (the U-frame) needs to be able to withstand greater impact and vibration in the rotation process. Therefore, the system has higher requirements for the azimuth axis, and $\mathrm{Si}-\mathrm{Al}$ alloy is selected as the processing material for the azimuth axis. In 
TABLe 2: Parameters of fan-type grating.

\begin{tabular}{lcccc}
\hline Position sensor & Quality $(\mathrm{g})$ & Measurement accuracy (arc-second) & Distinguishability (arc-second) & Maximum measured speed (rpm) \\
\hline MicroE & 5 & \pm 3.9 & 0.618 & 824 \\
\hline
\end{tabular}

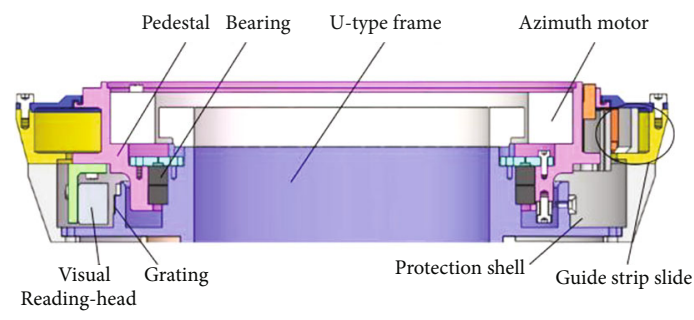

Figure 5: Rotary shafting structure.

order to obtain better stiffness and strength of the bearing end cover, the inner and outer end cover of the bearing are made of Si-Al alloy. According to analysis, In the course of rotation, azimuth shaft bears both axial and radial load, so the angular contact ball bearing is selected for use.

2.1.4. Modal Analysis of U-Frame Mechanical Structure. The U-type frame is an important part of the turntable; its structure directly affects the dynamic and static characteristics of the whole system [17], because of occupying a large ratio on the quality of the whole turntable on the U-type frame, reasonable light-weighting is very important for the weight of the whole system in the U-type frame; it can not only reduce the static deformation but also greatly improve the accuracy of turntable and optimize the 3D model of the U-frame (Figure 6).

The ultimate goal of modal analysis is to identify the modal parameters of the system and provide the basis for the vibration characteristic analysis [18], vibration fault diagnosis and prediction as well as the optimal design of structural dynamic characteristics. In order to prevent the mechanical structure from resonating or vibrating at a fixed frequency, we should conduct modal analysis on the weak parts of the mechanical structure and determine whether the mechanical structure is stable according to the results. Its general equation is as follows:

$$
[\mathrm{M}]\{\ddot{\mathrm{u}}\}+[\mathrm{C}]\{\dot{\mathrm{u}}\}+[\mathrm{K}]\{\mathrm{u}\}=\{\mathrm{f}(\mathrm{t})\} .
$$

$[\mathrm{M}]\{\ddot{\mathrm{u}}\}+[\mathrm{C}]\{\dot{\mathrm{u}}\}$ is the nondamping free vibration of the system, and $[\mathrm{K}]\{\mathrm{u}\}$ is the harmonic vibration of the system. According to the task requirements of the experiment, the order 6 mode analysis of the U-frame and the support is carried out. The results are shown in Figure 7 and Table 4. It can be seen from the modal analysis results that the Uframe can meet the stiffness requirements.

2.1.5. Error Analysis of SLR Mirror Turntable. In the work of shafting, there are many factors affecting the accuracy of shafting, $[19,20]$, but there are three main factors affecting the pointing accuracy, namely, the shafting sloshing error, the torque motor control, and the position element detection error and random error.
(1) Angular Sloshing Error of Elevation Axis.

(i) Elevation axis sloshing error

Matching bearing angular sloshing error is about 1.5". At the same time, considering the machining error of the Uframe, as well as factors such as machining concentricity, fit clearance, and assembly measurement error, the equivalent synthetic clearance of elevation axis and radial direction is as follows:

$$
\Delta_{\mathrm{e} 1}=0.002 \mathrm{~mm} \text {. }
$$

The angular sloshing error is $\delta_{e 1}=\left(\Delta_{e 1} / L_{1}\right) \times 206265^{\prime \prime}$.

Left- and right-end bearing span is $L_{1}=128 \mathrm{~mm}$, so $\delta_{e 1}$ $=3.22^{\prime \prime}$.

(ii) Positioning error of position element

Fan-shaped grating is adopted to achieve precision as $\delta_{e 2}=3.9^{\prime \prime}$.

According to the experience, the random error can be controlled at $\delta_{e 3}=0.3$ ".

Therefore, the pointing accuracy of elevation direction is as follows:

$$
\delta_{E}=\sqrt{\delta_{e 1}^{2}+\delta_{e 2}^{2}+\delta_{e 3}^{2}}=5.06^{\prime \prime} .
$$

\section{(2) Azimuth Shafting Angular Sloshing Error.}

(i) Azimuth shafting sloshing error

The calculation is based on the matching shafting angular sloshing error of 1.5", and the equivalent synthetic clearance in the azimuth and axial direction caused by the machining error of the axis and shafting block, fitting clearance, assembly measurement error, and other factors is as follows: $\Delta_{a 1}=0.003 \mathrm{~mm}$.

The angular sloshing error:

$$
\delta_{a 1}=\frac{\Delta_{a 1}}{L_{2}} \times 206265^{\prime \prime}
$$

Shafting to elevation axis span $L_{2}=120 \mathrm{~mm}$, so $\delta_{a 2}=$ $5.16^{\prime \prime}$.

(ii) Positioning error of position element

Renishaw grating is adopted to achieve precision as $\delta_{a 2}$ $=1^{\prime \prime}$. 
TABLE 3: Main parameters of azimuth motor.

\begin{tabular}{lcccccc}
\hline Motor & $\begin{array}{c}\text { Peak voltage at locked } \\
\text { rotor }(\mathrm{V})\end{array}$ & $\begin{array}{c}\text { Electricity } \\
(\mathrm{A})\end{array}$ & $\begin{array}{c}\text { Continuous locked-rotor } \\
\text { torque }(\mathrm{nm})\end{array}$ & $\begin{array}{c}\text { Peak torque } \\
(\mathrm{nm})\end{array}$ & $\begin{array}{c}\text { Load inertia } \\
\left(\mathrm{kg} \cdot \mathrm{m}^{2}\right)\end{array}$ & $\begin{array}{c}\text { Rotate speed }(\mathrm{rad} / \\
\mathrm{min})\end{array}$ \\
\hline J150LST01B & 28 & 3 & 0.84 & 2.1 & 0.5 & 400 \\
\hline
\end{tabular}

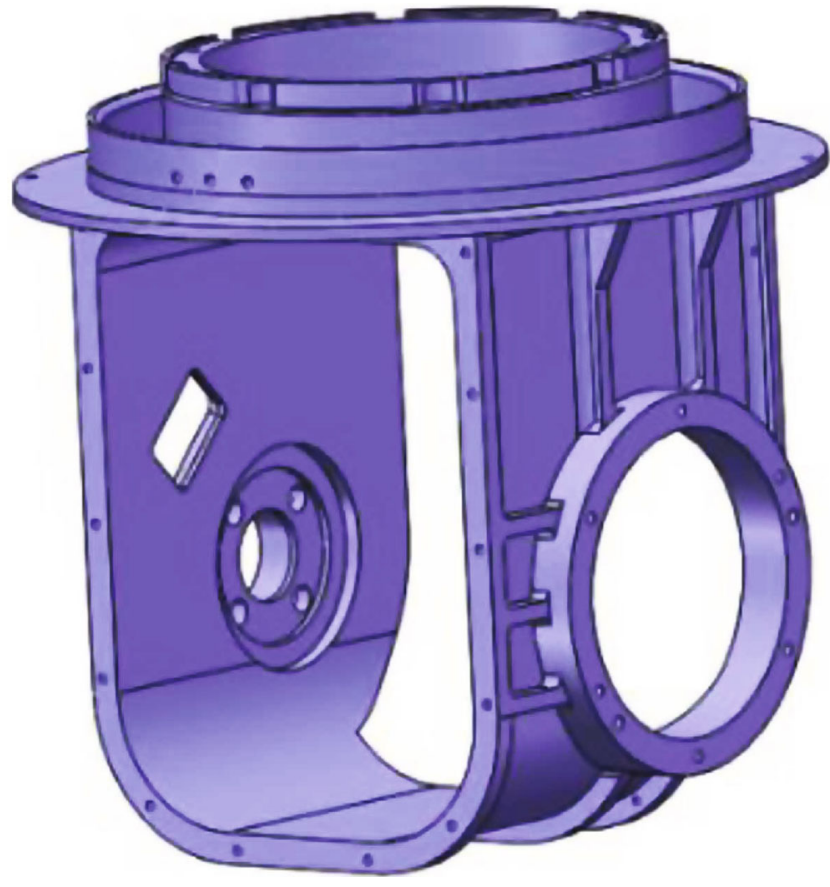

Figure 6: U-type frame structure.

(iii) According to the experience, the random error can be controlled at $\delta_{a 3}=0.3^{\prime \prime}$; therefore, the azimuth pointing accuracy of $\mathrm{U}$-frame structure is as follows:

$$
\delta_{A}=\sqrt{\delta_{a 1}^{2}+\delta_{a 2}^{2}+\delta_{a 3}^{2}}=5.26^{\prime \prime}
$$

The calculation results show that the design of the Uframe structure achieves the precision requirements of the rough tracking unit designed by the APT subsystem.

\subsection{The Structural Design of L-Type Rough Tracking Unit}

2.2.1. Shafting Design of Rough Tracking Structure. According to the functional indicators, in order to meet the requirements of technical parameters and enable as much light as possible to enter the parallel optical tube in parallel, the optical antenna and the parallel optical tube can be connected with a support, and an optical antenna is also able to communicate with three simulated target sources at the same time. The overall structure of the main optical receiver is shown in Figure 8.

(1) Elevating Axis Design. The system adopts the design scheme of a cross-tracking frame; the mirror deviates forward from the axis of the elevating axis, so as to get rid of the restriction of the support frame of elevating axis. In order to avoid the azimuth axis bearing the unbalanced torque caused by the eccentricity of elevating frame, the azimuth axis intersects the axis of the elevating axis, and the parallel transport of the mirror is small during rotation, which cannot affect the specular reflection efficiency; through the optimization of the structure design, we can avoid the interference among adjacent lens caused by parallel transport. Some components of elevating shafting mainly include elevating support frame, deep groove ball bearing, mirror, fan-type grating, and fan-type voice coil linear motor. The elevation axis structure is shown in Figure 9.

The elevating support frame is designed in an L-shape. This structure is convenient for axis installation and debugging, and the static deformation caused by the support frame rotation is relatively small. Although the stiffness of the structure is slightly weak, the motion of the elevating axis belongs to the swing cycle and has low stiffness requirements. Such voice coil motor can be fixed on the elevating support frame, not only taking advantage of the radial dimension of the elevating axis, but also shortening the dimension chain. When the voice coil motor swings at a finite angle, it drives the mirror to elevate. In order to reduce fan-type grating ruler track and elevating axis alignment error, the grating mounting plate, mirror support, and elevating axis shell are designed into a whole; in this way, the center of the arc-graduated track on the grating scale can be ensured to be on the same axis as the elevating axis during elevating motion, and the transmission error of the structure can be reduced to a certain extent, which makes the whole axis system more compact.

(2) Azimuth Shafting Design. Shafting structure is shown in Figure 10. Azimuth shafting components mainly include the position axle, bearing, azimuth motor, flange of grating, rotary grating, and shell. According to the load characteristics and system requirements, the hollow motor shaft is selected as the azimuth shaft. Both the motor and the circular grating adopt the shaft sleeve mode designed by the traditional turntable, so as to shorten the axial dimension of the whole shafting.

Azimuth shafting is designed as a single-ended fixed, ladder-shaped hollow shaft, which is installed in the order from top to bottom motor coil, DC torque motor, matching bearings, bearing inner and outer rings, grating joints, and rotating grating; the motor stator is connected and fixed by pressure coil and structural glue; the circular grating and the grating connector are connected and fixed by epoxy adhesive; the shell of bearing system is fixed; and the inner hollow axis of the bearing system is driven to rotate when the bearing motor rotates. In this way, when the motor rotates, the circular 

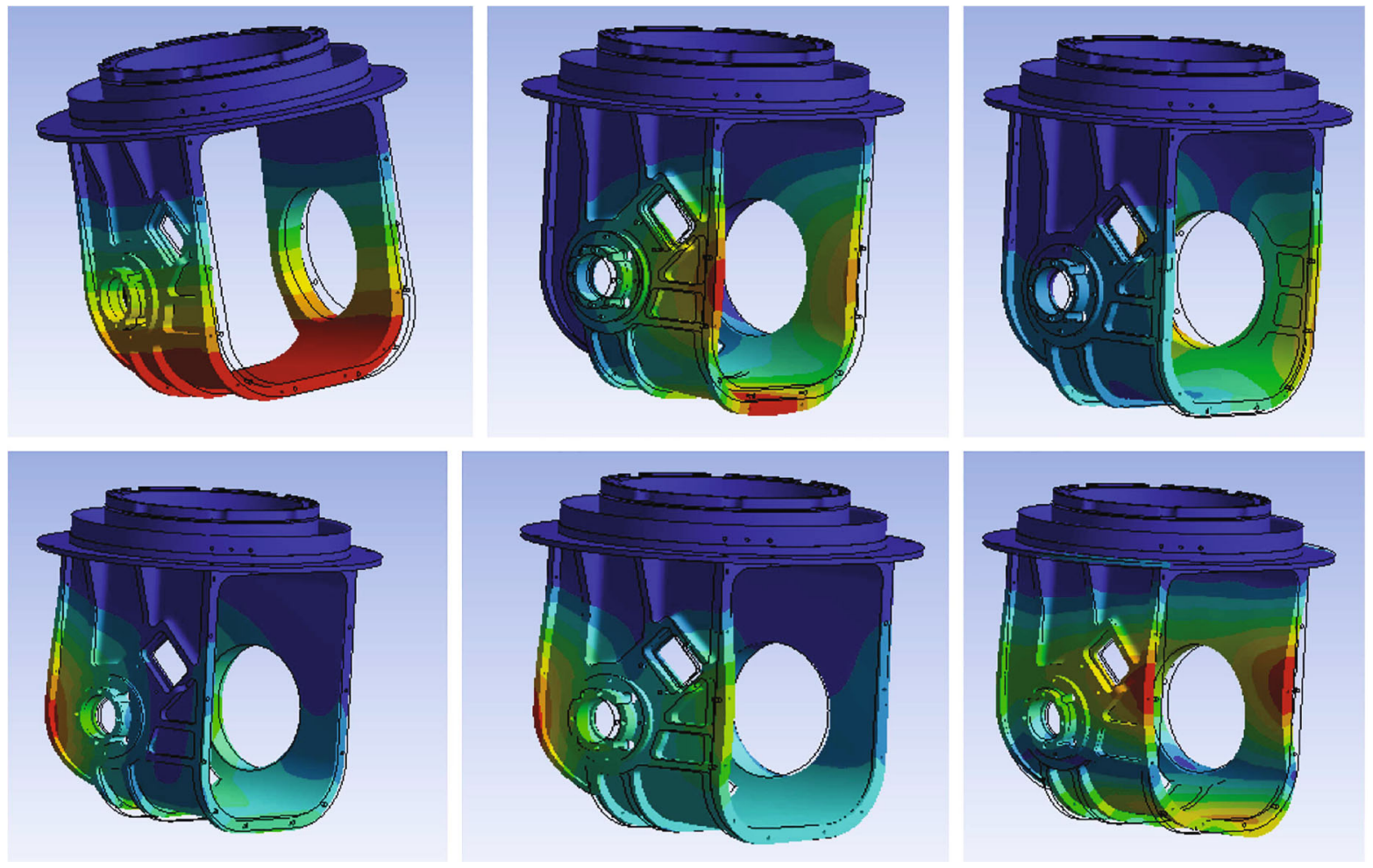

FIGURE 7: The results of U-type frame modal analysis.

TABle 4: The data of U-type frame modal analysis.

\begin{tabular}{lc}
\hline Model no. & Frequency (hertz) \\
\hline 1 & $437.37 \mathrm{~Hz}$ \\
2 & $1544.9 \mathrm{~Hz}$ \\
3 & $1621.4 \mathrm{~Hz}$ \\
4 & $2015.7 \mathrm{~Hz}$ \\
5 & $2312.8 \mathrm{~Hz}$ \\
6 & $2552.6 \mathrm{~Hz}$ \\
\hline
\end{tabular}

grating and elevating can be driven to rotate together, so as to achieve azimuth motion. The azimuth motor is Allied Motion's brushless DC torque motor, whose type is the same as the U-frame brushless DC torque motor.

2.2.2. Mechanical Structure Strength Analysis. If the one-tomany rough tracking system can operate normally, it is necessary to carry out static analysis on its weak parts and structure, and it must be ensured that each part meets the requirements of the experiment. As one of the weak parts in the system, the elevating L-type frame is analyzed for force analysis. The force acting on the outermost tip of the elevating axis will cause the maximum deformation of the L-frame. We analyzed from two situations, and the analysis results are shown in Figures 11 and 12.

The force direction is in the positive direction of $z$-axis and acts on the farthest end of the elevating axis.

The force direction is in the positive direction of $x$-axis and acts on the top end of the side support skeleton of Lframe.
It can be seen from the analysis results that the L-type frame can meet the stiffness requirements.

\subsubsection{Design Calculation and Selection of Key Components.} The L-frame shafting system of the laser communication terminal adopts the frame structure, which mainly consists of the bearing, motor, encoder, and so on. The parameters of the motor determine the feasibility of the structure to a certain extent. After investigation and research, the azimuth motor adopts the split DC brushless torque motor, which is very suitable for the high-precision turntable. Therefore, the azimuth motor chooses the brushless DC torque motor produced by Allied Motion, type MF0060008-A00-z. Due to the limitation of axial size, the elevating shaft system adopts voice coil motor, type VARS0008-026-00A, and its main technical indicators are shown in Table 5.

(1) Moment Checking Calculation of Azimuth Motor. The maximum angular acceleration of the optical receiver azimuth rotation is $2^{\circ} / \mathrm{s}^{2}$. After software analysis and modeling, it can be known that the weight of the bearing frame is $1.25 \mathrm{~kg}$ and the moment inertia about the bearing system is $0.00142 \mathrm{~kg} \cdot \mathrm{m}^{2}$.

$$
M=J \beta=\frac{0.00142 \times 2}{360 \times 6.28}=0.00005 \mathrm{Nm}
$$

The calculation shows that the selected motor meets the control requirements of the system. 


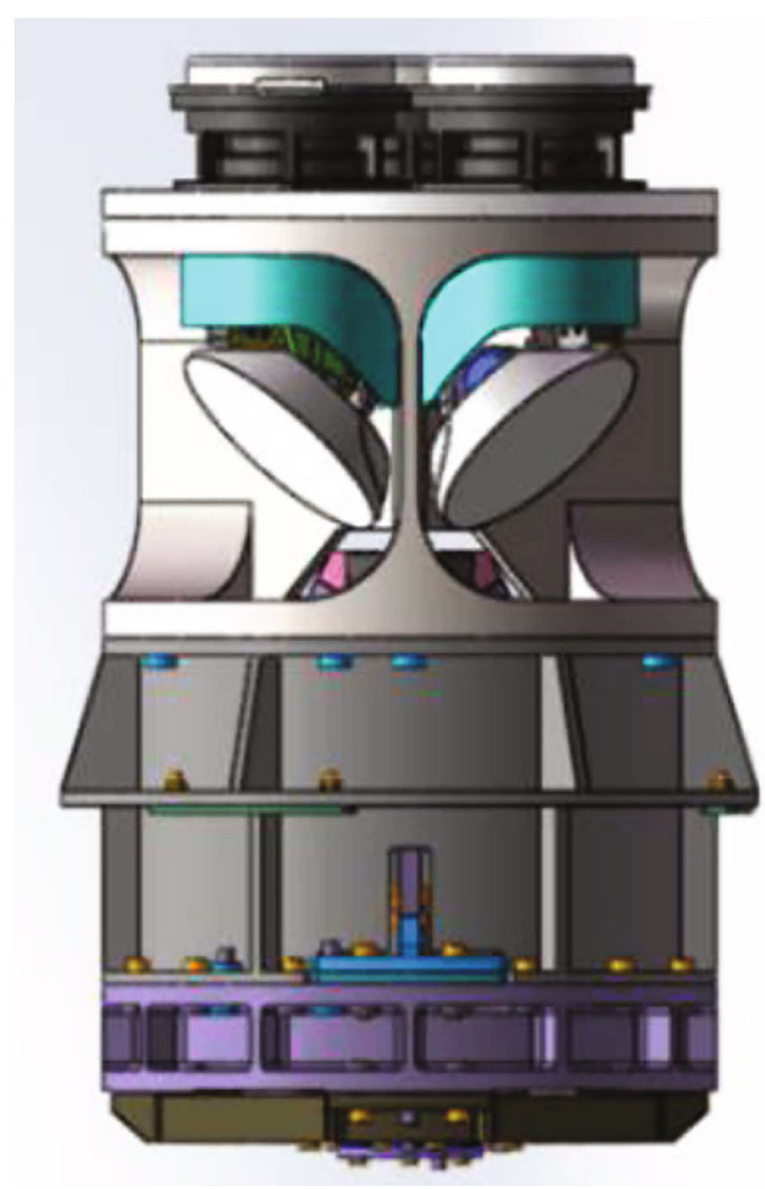

FIGURE 8: L-type architecture.

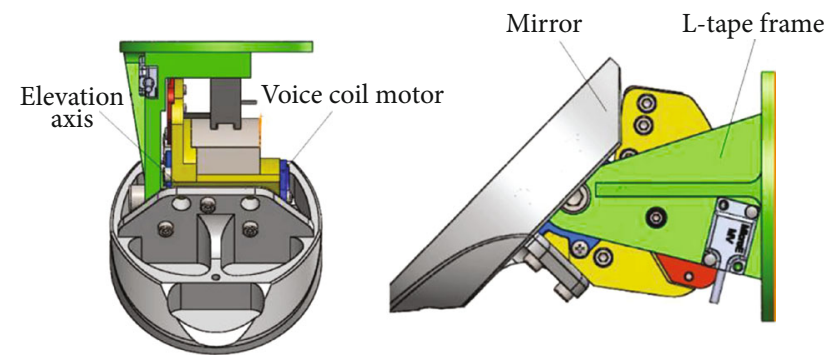

Figure 9: Elevation axis structure.

The motion of the elevating shafting selects the fan-type voice coil linear motor, type VARS0008-026-00A, and the main technical indicators are shown in Table 6.

(2) Torque Checking Calculation of Elevating Motor. After software analysis and calculation, the quality of support frame and mirror is about $0.461 \mathrm{~kg}$ during elevating rotation, moment of inertia is $0.000513 \mathrm{~kg} \cdot \mathrm{m}^{2}$. According to the parallel axis theorem of inertia [21],

$$
J_{z}=J_{c}^{\prime}+m k_{2}^{2}
$$

$J$ is the moment of inertia of the object, parallel to the $z$ axis and passing through the $C$ axis of the center of mass; $J_{c}$

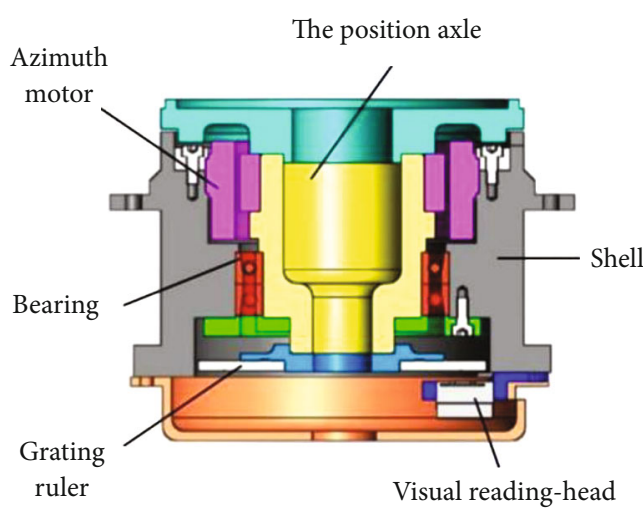

Figure 10: Azimuth shafting structure.

is the moment of inertia of the object, which is parallel to the $z$-axis and passing through the $C$ axis of the center of object; $m$ is the quality of the object; and $k_{2}$ is the distance between the $z$-axis and the center. According to calculating of the formula, the rotational inertia of the supporting frame is $328 \mathrm{~kg} \cdot \mathrm{mm}^{2}$ relative to the elevating axis, the rotational inertia of the mirror is $2864 \mathrm{~kg} \cdot \mathrm{mm}^{2}$ relative to the elevating axis, the rotational inertia of the elevating half shaft relative to the elevating axis is $5.22 \mathrm{~kg} \cdot \mathrm{mm}^{2}$, the rotational inertia of the voice coil motor rotor relative to the elevating axis is $453 \mathrm{~kg} \cdot \mathrm{mm}^{2}$, the rotational inertia of rotor fitting relative to the elevating axis is $32.2 \mathrm{~kg} \cdot \mathrm{mm}^{2}$, the rotational inertia of the grating mounting plate relative to the elevating axis is $78.5 \mathrm{~kg} \cdot \mathrm{mm}^{2}$, and the inertia of the counterweight relative to the elevating axis is $982 \mathrm{~kg} \cdot \mathrm{mm}^{2}$.

The maximum angular acceleration of the system is $0.52 \mathrm{rad} / \mathrm{s}^{2}$, the safety factor is 1.5 , and the torque required for the turntable is $M_{1}=0.004 \mathrm{Nm}$. Combined with other factors, this elevating motor is selected to meet the requirements of use.

2.2.4. Shafting Accuracy Analysis. In the work of shafting, there are many factors affecting the accuracy of shafting, among which the main factors affecting the pointing accuracy are shafting sloshing error, torque motor control, position element detection error, and random error [22, 23].

\section{(1) Elevating Angular Sloshing Error.}

\section{(i) Elevating sloshing error}

The matching bearing angular sloshing error is about 1.5 "; at the same time, considering the machining error of the L-type frame, as well as factors such as machining concentricity, fit clearance, and assembly measurement error, the equivalent synthetic clearance of the elevating axis and radial direction is as follows:

The angular sloshing error is

$$
\delta_{e 1}=\frac{\Delta_{e 1}}{L_{1}} \times 206265^{\prime \prime} .
$$




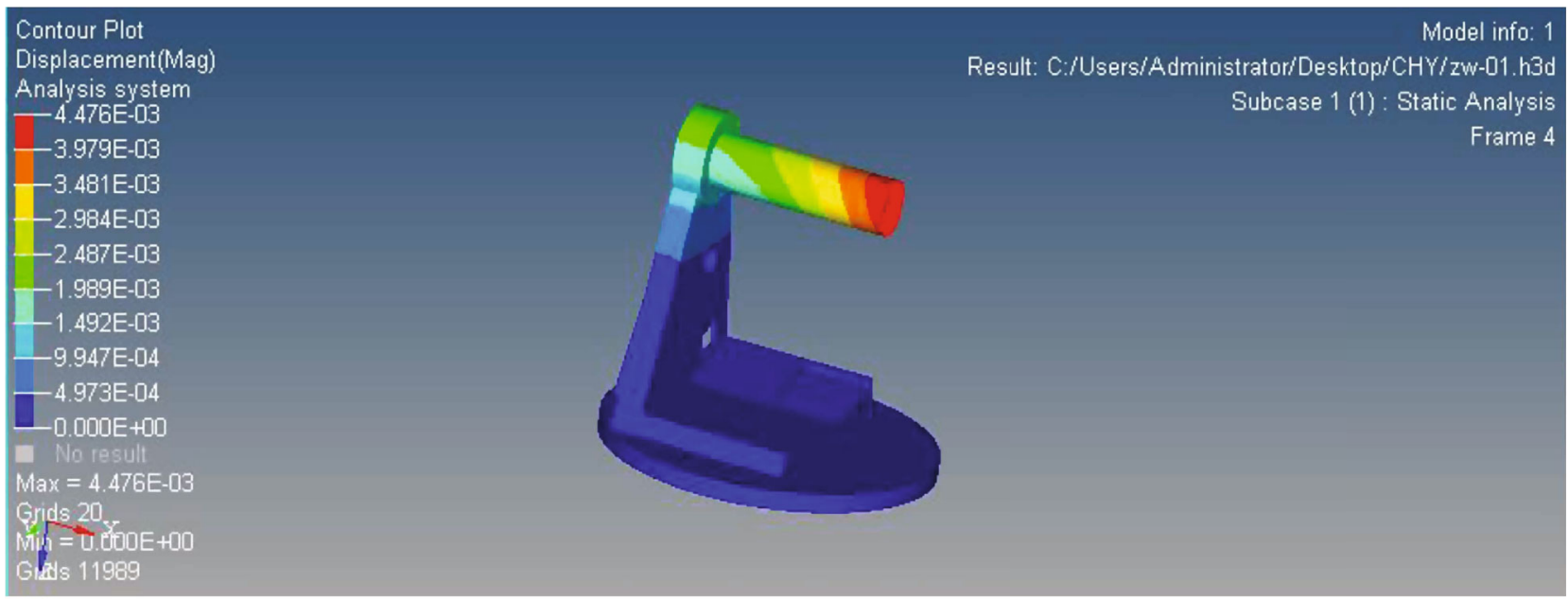

FIGURE 11: The displacement cloud diagram of the $z$-axis of L-type structure.

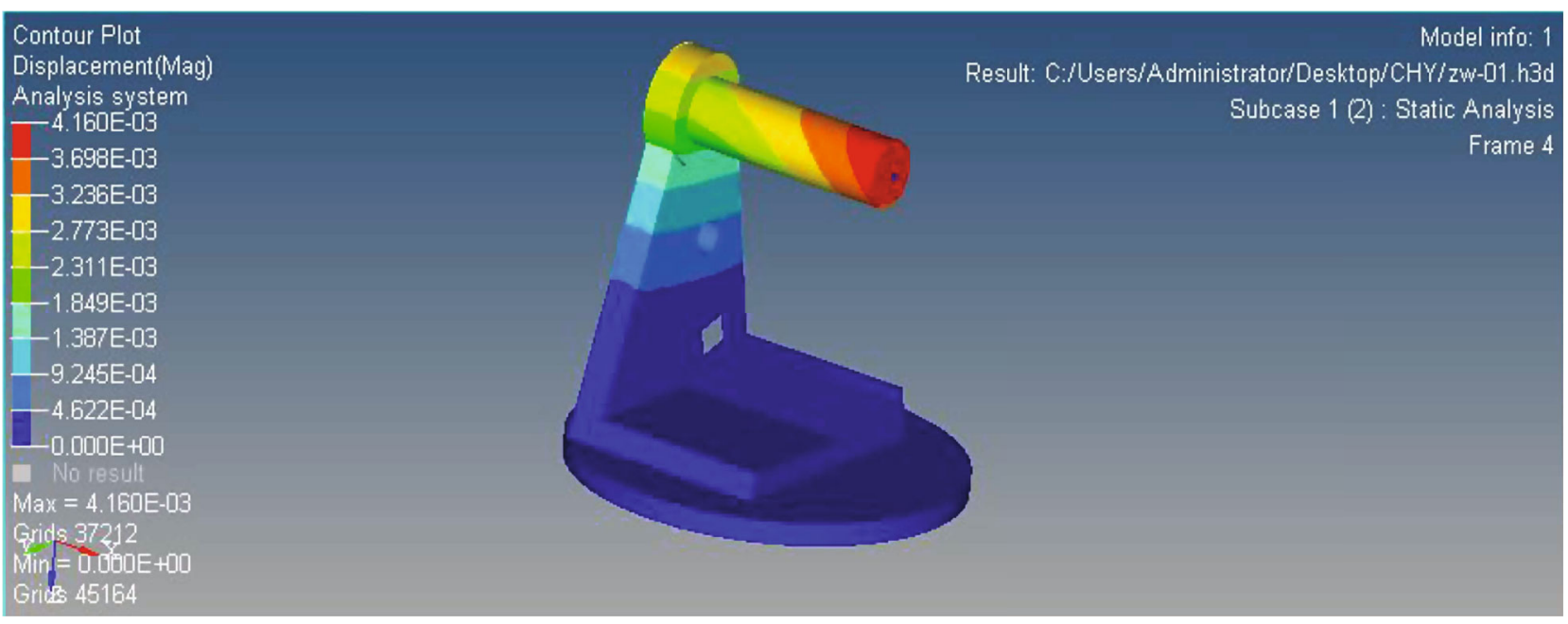

FIGURE 12: The displacement cloud diagram of the $x$-axis of L-type structure.

TABLE 5: Main parameters of azimuth motor.

\begin{tabular}{lccccc}
\hline Motor & $\begin{array}{c}\text { Peak voltage at } \\
\text { locked rotor (V) }\end{array}$ & Electricity (A) & $\begin{array}{c}\text { Continuous locked-rotor } \\
\text { torque }(\mathrm{nm})\end{array}$ & Peak torque (nm) & $\begin{array}{c}\text { Load inertia }\left(\mathrm{kg} \cdot \mathrm{m}^{2}\right) \\
(\mathrm{rad} / \mathrm{min})\end{array}$ \\
\hline MF0060008-A00-Z & 24 & 0.773 & 0.019 & 0.337 & $2.131 E-0.5$ \\
\hline
\end{tabular}

TABLE 6: Main parameters of elevating motor.

\begin{tabular}{lccccc}
\hline Motor & $\begin{array}{c}\text { Peak voltage at locked-rotor } \\
(\mathrm{V})\end{array}$ & $\begin{array}{c}\text { Electricity } \\
(\mathrm{A})\end{array}$ & $\begin{array}{c}\text { Continuous locked-rotor } \\
\text { torque }(\mathrm{nm})\end{array}$ & $\begin{array}{c}\text { Peak torque } \\
(\mathrm{nm})\end{array}$ & $\begin{array}{c}\text { Load inertia } \\
\left(\mathrm{kg} \cdot \mathrm{m}^{2}\right)\end{array}$ \\
$\begin{array}{l}\text { Voice coil } \\
\text { motor }\end{array}$ & 6 & 1.78 & 0.05 & 0.08 & $\begin{array}{c}\text { Rotate speed } \\
(\mathrm{rad} / \mathrm{min})\end{array}$ \\
\hline
\end{tabular}

The left- and right-end bearing span is $L_{1}=52 \mathrm{~mm}$; therefore, $\delta_{e 1}=5.95^{\prime \prime}$.

(ii) Positioning error of position element

The absolute induction synchronizer is adopted, and the absolute precision reaches $\delta_{e 2}=2$ ". According to the experience, the random error can be controlled at $\delta_{e 3}=0.3^{\prime \prime}$.
Therefore, the pointing accuracy of elevating direction is as follows:

$$
\delta_{E}=\sqrt{\delta_{e 1}^{2}+\delta_{e 2}^{2}+\delta_{e 3}^{2}}=6.28^{\prime \prime}
$$

(2) Azimuth Shafting Angular Sloshing Error. 

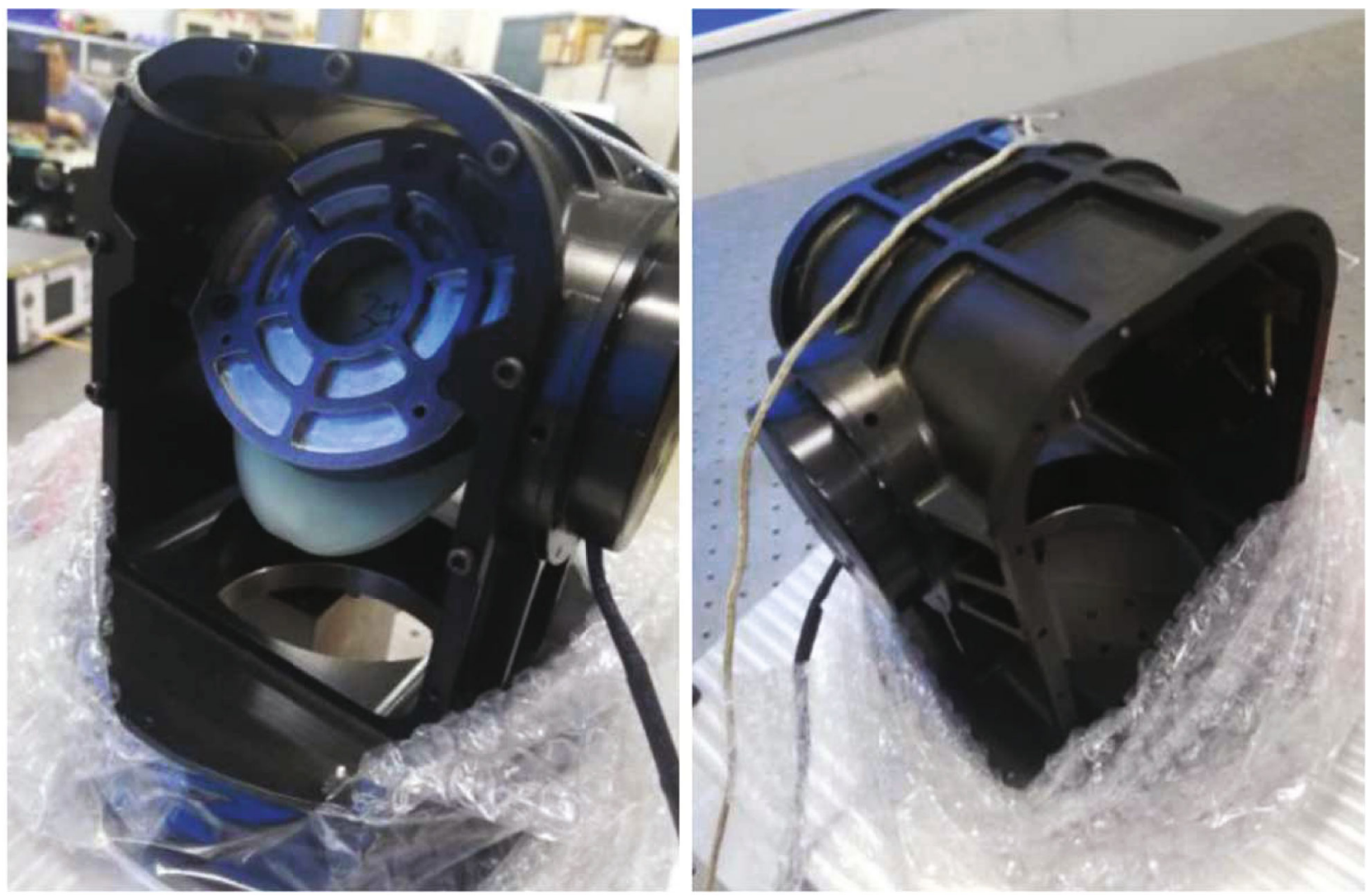

FIgURE 13: Sample machine of U-type frame.

(i) Azimuth shafting sloshing error

The calculation is based on the matching shafting angular sloshing error 1.5"; at the same time, considering the machining error of axis and shafting block, fitting clearance, assembly measurement error, and other factors, the azimuth-axial diameter equivalent synthetic clearance is as follows:

$$
\Delta_{a 1}=0.0015 \mathrm{~mm}
$$

The angular sloshing error is

$$
\delta_{a 1}=\frac{\Delta_{a 1}}{L_{2}} \times 206265^{\prime \prime} .
$$

Upper and lower shafting span is $L_{2}=58 \mathrm{~mm}$; therefore, $\delta_{a 1}=5.33^{\prime \prime}$.

(ii) Positioning error of position element

Adopting relative induction synchronizer, the absolute precision achieves $\delta_{a 2}=2^{\prime \prime}$.

(iii) Random error

According to experience, the random error can be controlled at $\delta_{a 3}=0.3^{\prime \prime}[24]$.

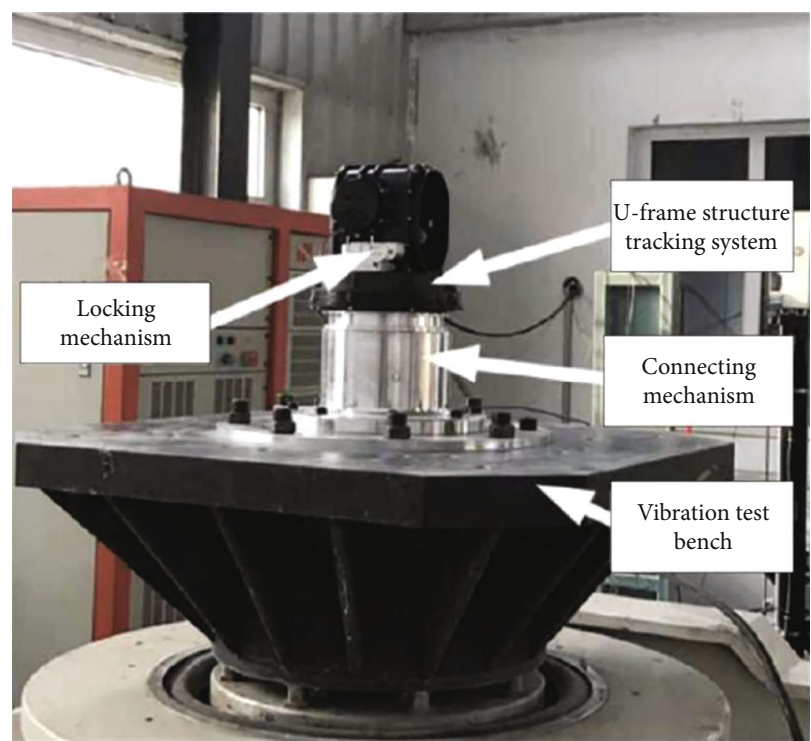

FIgURE 14: Vibration testing of U-type frame.

Therefore, the azimuth pointing accuracy is as follows: $\delta_{A}=\sqrt{\delta_{a 1}^{2}+\delta_{a 2}^{2}+\delta_{a 3}^{2}}=5.7^{\prime \prime}$.

Therefore, the comprehensive pointing accuracy of $2 \mathrm{D}$ turntable with L-frame structure is better than 6", and the comprehensive pointing accuracy can achieve the design requirements. 


\section{Conclusion}

In summary, it can be seen from the design of payloads of the $\mathrm{L}$ - and U-frame rough tracking units that both structures can meet the technical requirements of orbital microstar laser communication. However, the strength and reliability of the U-frame structure is better than that of the L-frame structure, and the comprehensive pointing accuracy is better than that of the L-frame structure. Therefore, we choose the U-frame structure SLR tracking and pointing system for processing and assembly, so as to carry out experimental verification of the principle prototype. A sample machine of the U-type frame is shown in Figure 13.

It is necessary to test the technical parameters and to verify the working performance for the optical pointing, acquisition, and tracking (PAT) of an intersatellite lasercom terminal on the ground in a laboratory [25]. Vibration testing of the U-type frame is shown in Figure 14.

Therefore, in the constant temperature laboratory environment, we carried out a random vibration environment test of the whole machine, with the test magnitude of $12 \mathrm{~g}$, to simulate the influence of the spatial random vibration on the structure and to verify the calculated data. The test results show that the U-type SLR tracking and pointing system is reliable. At the same time, the structure improves the ability of the tracking and sighting system to resist the transport mechanical environment, and its structure does not affect the precise parts of the tracking and sighting system; thus, it is ensured that the rough tracking accuracy achieves the requirements of low-orbit microstar laser communication technology.

\section{Data Availability}

The data used to support the findings of this study are available from the corresponding author upon request.

\section{Conflicts of Interest}

The authors declare that they have no known competing financial interests or personal relationships that could have appeared to influence the work reported in this paper.

\section{References}

[1] K. Suri, "Laser satellite communication fundamentals and applications," International Journal of Engineering and Technical Research, vol. 6, no. 3, pp. 2454-4698, 2016.

[2] O. Cierny and K. L. Cahoy, "On-orbit beam pointing calibration for nanosatellite laser communications," Optical Engineering, vol. 58, no. 4, 2019.

[3] M. Toyoshima, T. Fuse, D. R. Kolev et al., "Current status of research and development on space laser communications technologies and future plans in NICT," in 2015 IEEE International Conference on Space Optical Systems and Applications (ICSOS), New Orleans, LA, USA, 2015.

[4] H. Qin, J. Y. Ma, S. J. Chen et al., "Identification of haploid maize kernel using NIR spectroscopy in reflectance and transmittance modes: a comparative study," Spectroscopy and Spectral Analysis, vol. 36, no. 1, pp. 292-297, 2016.
[5] J. Luypaert, M. H. Zhang, and D. Massart, "Feasibility study for the use of near infrared spectroscopy in the qualitative and quantitative analysis of green tea, Camellia sinensis (L.)," Analytica Chimica Acta, vol. 478, no. 2, pp. 303-312, 2003.

[6] S. J. Chen, L. Zhang, J. C. Wu, C. K. Li, and J. Y. Wang, "Realization and optimization of fine tracking system of free space laser communication," Journal of Infrared and Millimeter Waves, vol. 37, no. 1, pp. 35-41, 2018.

[7] A. Saksonov, S. Arnon, and N. S. Kopeika, "Vibration noise control in laser satellite communication," Proceedings of SPIE, vol. 4365, pp. 188-194, 2001.

[8] G. Duorui, L. Tianlun, S. Yue et al., "Latest developments and trends of space laser communication," Chinese Optics, vol. 11, no. 6, pp. 901-913, 2018.

[9] W. Wang, Optimization design and analysis of "TXZ" microsatellite structure, Nanjing University of Aeronautics and Astronautics, 2008.

[10] A. Biswas, J. M. Kovalik, M. Srinivasan et al., "Deep space laser communications," Free-space Laser Communication \& Atmospheric Propagation XXVIII, vol. 9739, article 97390Q, 2016.

[11] J. B. Stewart, J. D. Moores, and A. S. Fletcher, "Comparing adaptive optics approaches for NASA LCRD ground station," SPIE, vol. 8610, no. 10, 2013.

[12] G. Shijie, W. Jiabin, L. Yongkai, M. Shuang, N. Yanjun, and Y. Huisheng, "Development status and trend of micro-satellite laser communication systems," Chinese Optics, vol. 13, no. 6, pp. 1171-1181, 2020.

[13] Z. Zhao, Z. Tang, and L. Li, "Research on airborne laser communication technology," in 2013 Third International Conference on Instrumentation, Measurement, Computer, Communication and Control, Shenyang, China, 2014.

[14] Q. L. Hu, Z. H. Li, L. Yang, K. Qiao, and X. J. Zhang, “Overview of research on space laser communication tracking and pointing technology," Chemical Engineering Transactions, vol. 46, pp. 1015-1020, 2015.

[15] S. J. Chen, H. K. Wang, L. G. Zheng, and B. Yang, “The stabilization analysis of laser weapons' compound-axis tracking and pointing," Fire Control \& Command Control, vol. 37, no. 4, 2012.

[16] M. Manngård, W. Lund, J. Keski-Rahkonen et al., "Estimation of propeller torque in azimuth thrusters," IFAC-Papers OnLine, vol. 52, no. 21, pp. 140-145, 2019.

[17] Q. Y. Tan, Y. G. Gao, X. Q. Wang, X. Y. Xue et al., "Dynamic analysis and optimization of inner supporting structure for laser emission turntable," Journal of Engineering Design, vol. 17, no. 3, pp. 185-186, 2010.

[18] Y. Long, Z. J. Teng, and F. S. Zhao, The present status and development trends of finite element modal analysis, Hunan Agricultural Machinery, 2009.

[19] J. Shao, S. L. Sun, C. L. Wang, L. W. Sun, and P. J. Zhang, "Numerical analysis for surface deformation of a spherical reflector in thermal environment," Optical Technique, vol. 32, S1, 2006.

[20] T. Wang, M. Zhu, S. Yin, H. Jia, and G. Sun, “Analysis of LOS pointing error derived from precision of shafting in stabilization mechanism," Infrared and Laser Engineering, vol. 40, no. 11, pp. 2265-2269, 2011.

[21] A. R. Abdulghany, "Generalization of parallel axis theorem for rotational inertia," American Journal of Physics, vol. 85, no. 10, pp. 791-795, 2017. 
[22] F. D. Jun and Z. L. Zheng, "Analysis of the axial accuracy of the GD-220 photoelectric theodolite," Optics \& Precision Engineering, vol. 10, no. 4, pp. 416-419, 2002.

[23] L. I. Song and L. P. Zhang, "Design and accuracy analysis for drift adjusting rotary axes of space camera," Optics and Precision Engineering, vol. 2, 2004.

[24] J. H. Yang, Y. Liu, G. W. Chen, Z. S. Wei, and D. F. Xing, “A modeling method for random error of micromechanical gyroscope based on the improved EMD," Chinese Journal of Scientific Instrument, vol. 12, pp. 196-204, 2019.

[25] L. Liu, L. Wang, J. Sun et al., "An integrated test-bed for PAT testing and verification of inter-satellite lasercom terminals," Proceedings of SPIE, vol. 6709, 2007. 